\title{
Space Photovoltaic Concentrator Using Robust Fresnel Lenses, 4-Junction Cells, Graphene Radiators, and Articulating Receivers
}

\author{
Mark O’Neill $^{1}$, A.J. McDanal ${ }^{1}$, Henry Brandhorst ${ }^{2}$, Brian Spence ${ }^{3}$, Shawn Iqbal ${ }^{3}$, Paul Sharps ${ }^{4}$, \\ Clay McPheeters ${ }^{4}$, Jeff Steinfeldt ${ }^{4}$, Michael Piszczor ${ }^{5}$, Matt Myers ${ }^{5}$ \\ ${ }^{1}$ Mark O’Neill, LLC, Keller, TX 76248 USA, ${ }^{2}$ Carbon-Free Energy, LLC, Auburn, AL 36830 USA, \\ ${ }^{3}$ Deployable Space Systems, Inc., Goleta, CA 93117 USA, ${ }^{4}$ SolAero Technologies, Albuquerque, NM \\ 87123 USA, ${ }^{5}$ NASA Glenn Research Center, Cleveland, OH USA
}

\begin{abstract}
At the 42nd PVSC, our team presented recent advances in our space photovoltaic concentrator technology. These advances include more robust Fresnel lenses for optical concentration, more thermally conductive graphene radiators for waste heat rejection. improved color-mixing lens technology to minimize chromatic aberration losses with 4-junction solar cells, and an articulating photovoltaic receiver enabling single-axis sun-tracking, while maintaining a sharp focal line despite large beta angles of incidence. In the past year, under a NASA Phase II SBIR program, our team has made much additional progress in the development of this new space photovoltaic concentrator technology, as described in this paper.

Index Terms - concentrator, Fresnel lens, multijunction cells, ultralight, graphene. color-mixing.
\end{abstract}

\section{INTRODUCTION AND SUMMARY}

As discussed in our team's paper at the $42^{\text {nd }}$ PVSC, the TacSat 4 flight experiment (2011-2012) included one stretched linear Fresnel lens focusing sunlight at $8.5 \mathrm{X}$ geometric concentration ratio $(8.5 \mathrm{~cm}$ wide lens) onto three seriesconnected Emcore ATJM cells $(1.0 \mathrm{~cm}$ active width $)$ assembled into a fully encapsulated dielectrically isolated photovoltaic receiver with a single 500 micron thick $\mathrm{CMG}$ coverglass over the receiver (about $11 \mathrm{~cm}$ long). Over the first six months of the mission, the power degradation of this photovoltaic concentrator unit was only $13 \%$ compared to $30 \%$ for neighboring Emcore BTJM one-sun cells under 150 micron thick CMG coverglass, as expected [1]. But, between the seventh month and the thirteenth month of the flight, the weak pre-tensioned silicone lens material suffered a mechanical failure after radiation embrittlement led to higher tear stress and lower tear strength [2]. Since this failure, our team has developed far more robust lenses and made significant improvements in all areas for the Fresnel lens photovoltaic concentrator technology. This paper summarizes technology advances in the past year, since our paper at the last PVSC [3].

Since May 2015, our team has been working under a NASA Phase II SBIR contract to develop a new photovoltaic concentrator including the following three key elements:

- A flat Fresnel lens comprising 100-micron tall silicone prisms (DC 93-500) molded onto a 50 micron thick ceriadoped glass superstrate.

- 4-junction inverted metamorphic (IMM) solar cells.

- Ultra-thin graphene sheet waste-heat radiator.

\section{New BASEline CONCENTRATOR MODULE}

To minimize the parts-count and to enable later massproduction of the new concentrator technology, our team has selected a baseline concentrator module, shown in Fig. 1, as the basic building block of the new array. The size of the optical element was selected to match the largest available size for a 50 micron thick toughened ceria-doped microsheet glass superstrate. Qioptiq is making the $10 \mathrm{~cm} \times 10 \mathrm{~cm} C M G$ glass. We are molding silicone (Dow Corning DC93-500) prisms onto the inner surface of the glass superstrate to form two sideby-side linear Fresnel lenses. The triangular prisms have a max height of 100 microns, with a mass-effective thickness of only 50 microns since the prisms only fill up half the volume of the prismatic pattern layer thickness (the other half is void).

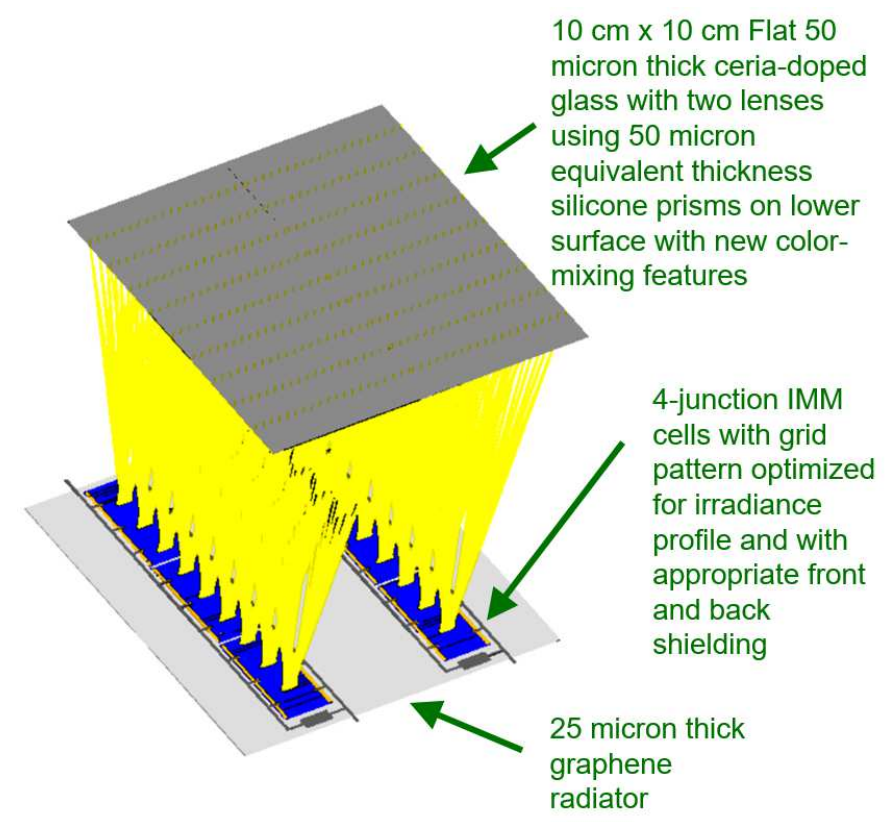

Fig. 1. New Baseline Concentrator Module.

The two lenses produce two focal lines on two photovoltaic receivers, each employing three 4-junction IMM cells. The lens aperture $(5 \mathrm{~cm})$ is $4 \mathrm{X}$ wider than the cell active width $(1.25$ $\mathrm{cm}$ ), to enable $\pm 2^{\circ}$ sun-pointing tolerance in the critical lateral (alpha) direction and $\pm 50^{\circ}$ in the longitudinal (beta) direction. 
The photovoltaic receivers are mounted onto 25-micron thick graphene sheet radiators for spreading and radiating the waste heat from the photovoltaic cells.

The lenses are specially designed and optimized to focus well despite large variations in beta angle, by employing a small articulation of the receivers relative to the lens. Fig. 2 shows a 3D-printed model with simulated articulating photovoltaic receivers properly positioned in the focal lines produced by the glass-silicone lens for both zero and $50^{\circ}$ beta angles. Note that the focal lines are sharp for both conditions. This 3D model will be used to fine-tune the articulation path to maximize cell current and power. Note the slots to allow for variation in receiver position relative to the nominal U-shaped path.
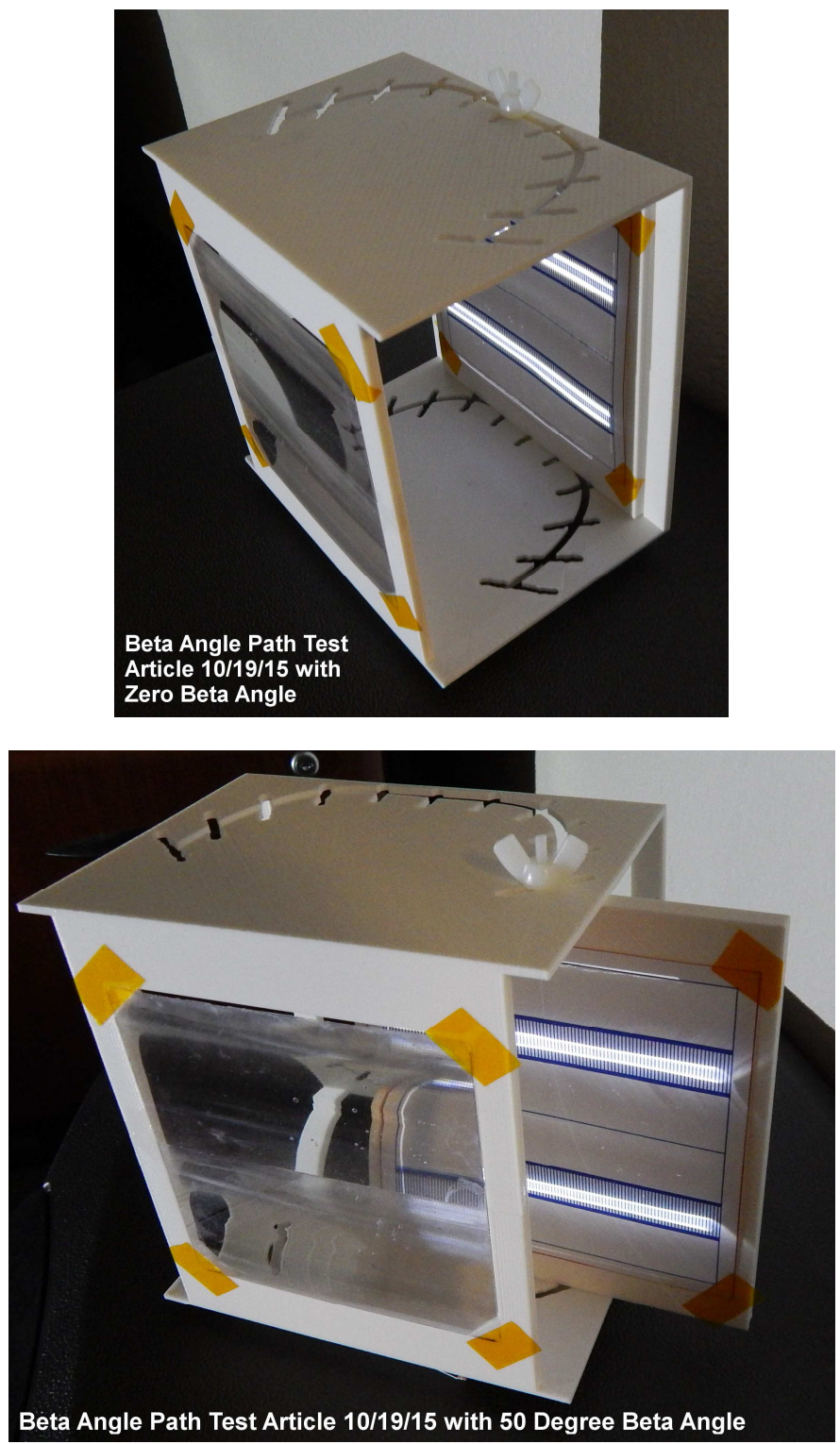

Fig. 2. Glass-Silicone Lens Showing Focal Lines on Simulated Articulating Photovoltaic Receivers at $0^{\circ}$ and $50^{\circ}$ Beta Angles (Patent Pending).

\section{4-JUNCTION IMM CELLS AND RECEIVERS}

The prismatic pattern of the new lens is optimized to provide exceptional color-mixing to avoid chromatic aberration losses in the 4-junction IMM cells used in the new concentrator module. Fig. 3 shows one of the three-cell circuits produced by SolAero for the new concentrator module. Each cell has a length of $3.2 \mathrm{~cm}$ and a total width of $1.5 \mathrm{~cm}$. The three cells are wired in parallel with a single bypass diode protecting the three-cell group. The cell string is slightly shorter than the 10 $\mathrm{cm}$ focal line produced by the lens. The tabbing and interconnection scheme provides a robust assembly for ground testing. Later flight units will be narrower and lighter. The 4junction IMM cells are supported on glass carriers beneath the cells. We believe this program is the first to use 4-junction IMM cells in a space concentrator application. Outstanding performance is expected from the new concentrator module.

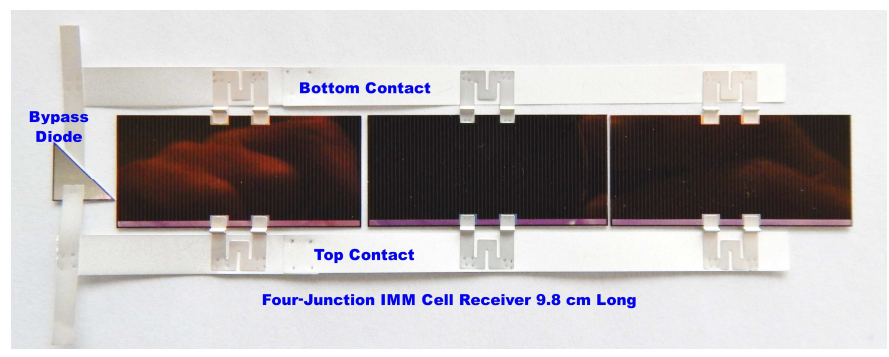

Fig. 3. SolAero 4-Junction IMM Cell Receiver Circuit.

\section{GRAPHENE RADIATOR DEVELOPMENT}

The 25-micron thick graphene sheet is not as robust as we would prefer, so our team has been investigating ways of strengthening the graphene sheet. One method is based on our alternate lens strengthening approach of adding a mesh to the silicone lens. Fig. 4 shows a small sample of graphene with an aluminum mesh bonded to it. This approach is attractive.

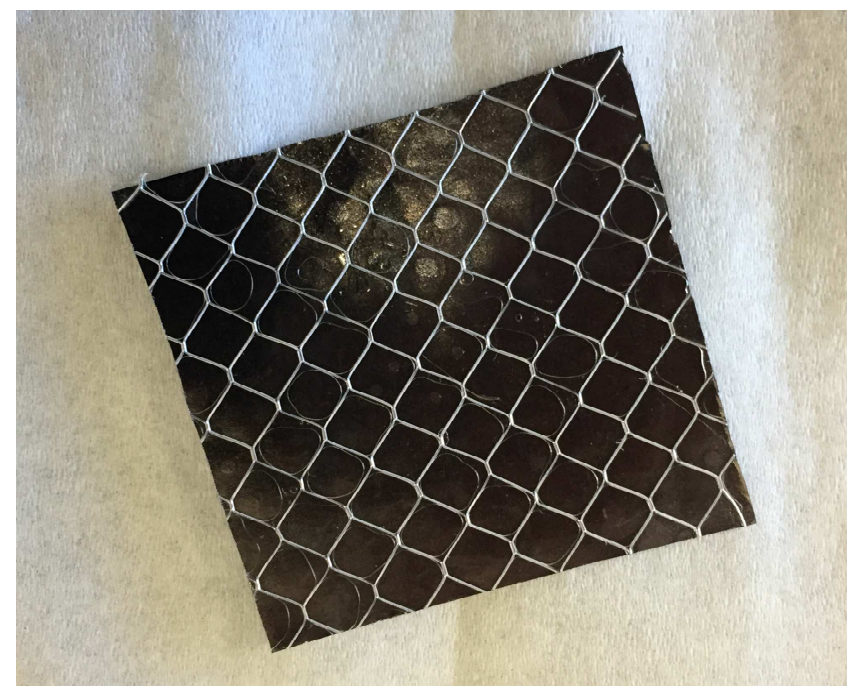

Fig. 4. Graphene Sheet with Aluminum Mesh Bonded to Surface. 
As presented in our paper at the last PVSC, graphene sheet offers a thermal conductivity to density ratio $10 \mathrm{X}$ better than aluminum sheet, and $5 \mathrm{X}$ better than carbon-fiber-reinforced sheet, and a 25-micron thickness is more than adequate for the concentrator module size shown in Fig. 1. However, our team was concerned about the emittance of the raw graphene, and AFRL measured the infrared properties which confirmed a relatively low 33\% emittance, as shown in Fig. 5. We then coated the graphene with a very thin layer of silicone and AFRL confirmed much better infrared properties, yielding more than double the emittance at $70 \%$, as also shown in Fig. 5.
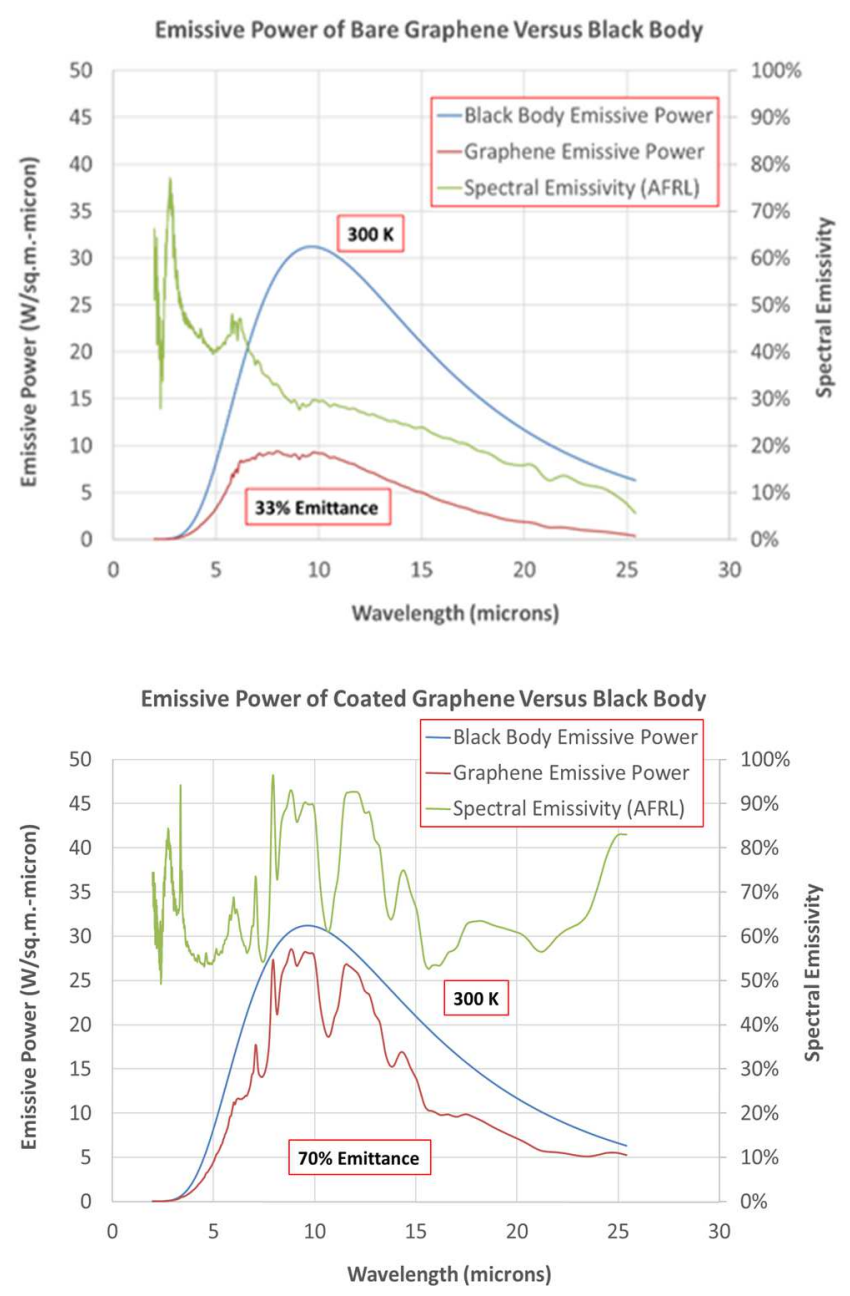

Fig. 5. Emittance of Silicone-Coated Graphene Sheet.

\section{Alternate Lens Material APPROACHES}

While the glass-silicone lens is our baseline design, we are also continuing to develop alternate lens material approaches which require no glass. Our present favorite alternate approach is a silicone lens with embedded aluminum mesh. Such a lens will of course employ a UV-rejection coating on the sunexposed surface, as have our non-glass-superstrate lenses for several successful flight experiments (including the silicone mini-dome lenses on PASP+ in 1994-1995, the 4-year-exposed
MISSE UVR-coated silicone samples on ISS, the UVR-coated stretched lens on TacSat 4), as well as many ground tests. To further explore this option, we previously conducted highenergy proton exposure testing at Auburn University at 5E12 $\mathrm{p}+/ \mathrm{cm}^{2}$ of $2.7 \mathrm{MeV}$ protons, with no measurable change in spectral transmittance. More recently, we conducted lowenergy proton exposure testing of the samples shown in Fig. 6. Dr. Scott Messenger of SRM Consulting LLC tested these samples at the Japan Atomic Energy Agency (JAEA), and they held up well for $1 \mathrm{E} 15 \mathrm{p}+/ \mathrm{cm}^{2}$ of $30 \mathrm{keV}$ protons, but suffered some darkening for $10 \mathrm{X}$ higher fluence. The spectral transmittance curves for the four samples were measured by Dr. Dave Wilt at AFRL, with results shown in Fig. 7. These samples were uncoated. We believe a thin UV-rejection coating would greatly extend the radiation hardness of this lens material approach. The mesh certainly strengthens the parts.

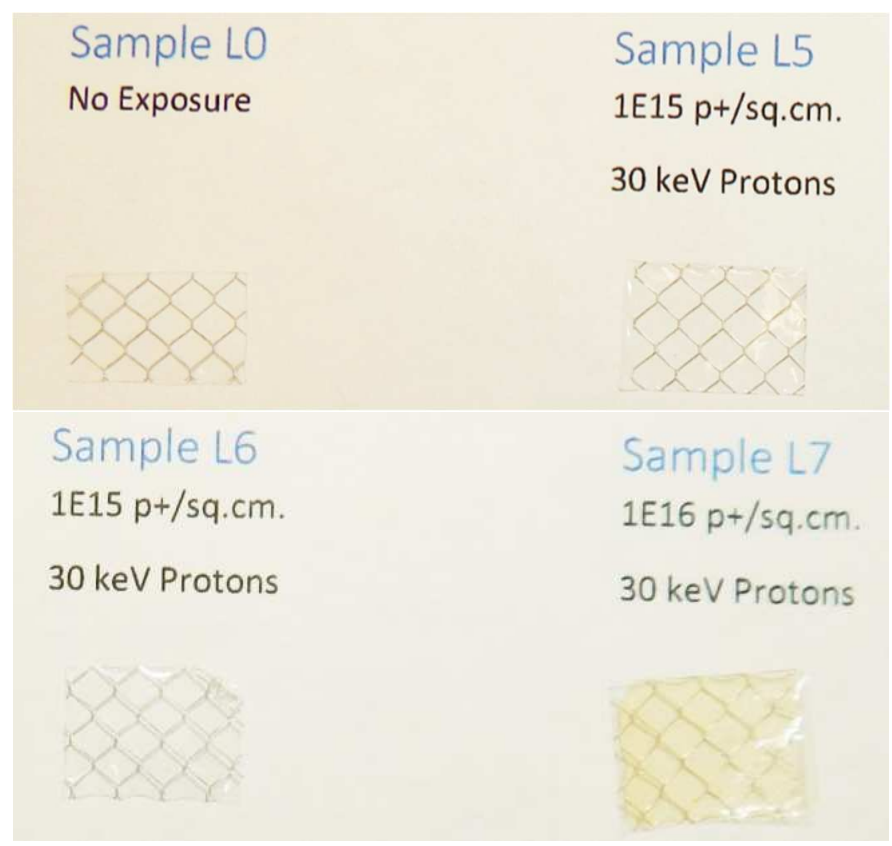

Fig. 6. Low-Energy Proton Exposed Samples.

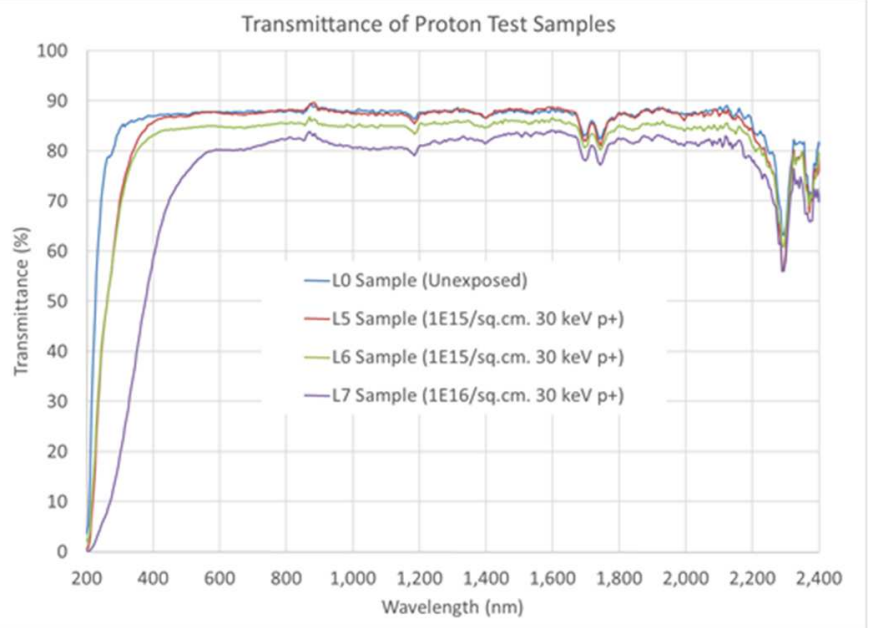

Fig. 7. AFRL-Measured Spectral Transmittance of Samples. 
An example lens of the alternate material approach is shown in Fig. 8. The lens is made from silicone with an embedded aluminum mesh which supports the lens and prevents tearing of the lens after a high dose of radiation exposure may embrittle and weaken the silicone material. The aluminum mesh also drastically reduces the effective coefficient of thermal expansion of the lens and provides an electrically conductive backbone which can be grounded to the spacecraft to minimize charging of the lens.

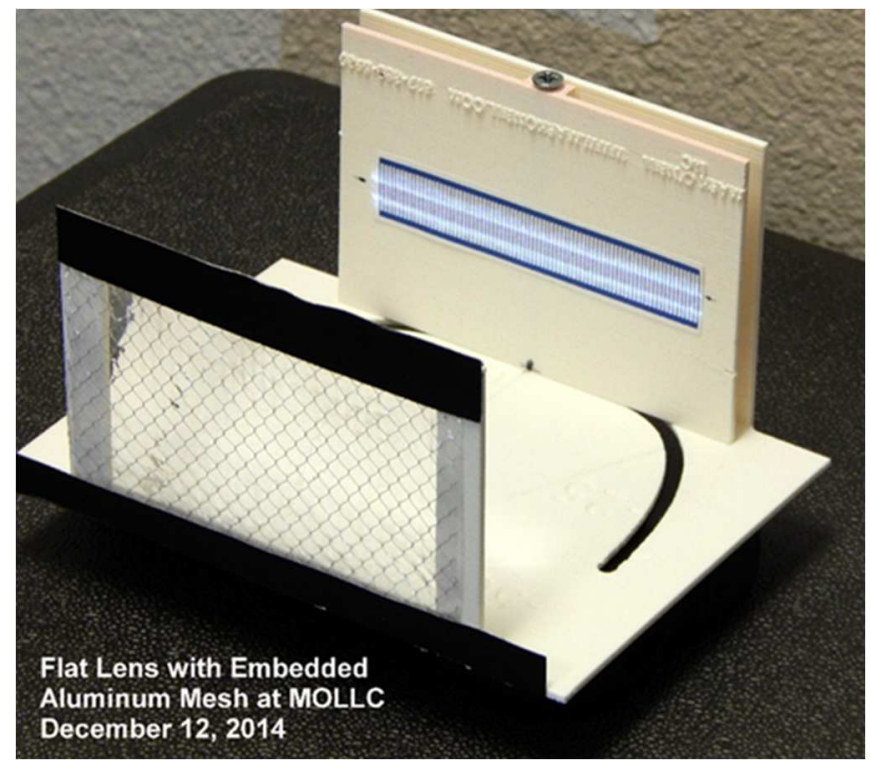

Fig. 8. Alternate Lens Material Approach: Silicone Lens with Embedded Aluminum Mesh (Patent Pending)

\section{LENS OPTICAL PERFORMANCE MEASUREMENTS AT DIFFERENT BETA ANGLES USING IMM CELLS IN ARTICULATING RECEIVERS}

One of the key innovative technologies being developed and demonstrated under an ongoing NASA Phase II SBIR program is the use of articulating photovoltaic receivers to accommodate large non-zero beta angles (longitudinal solar ray angles of incidence) to enable the new concentrator array to be deployed and supported on single-axis sun-tracking platforms. We have recently conducted a series of outdoor tests to measure the lens optical efficiency for various beta angles from zero to $\pm 50^{\circ}$ for a nominal articulation path based on analytical and visual results. We have also varied this path in these tests to see if it is indeed the best articulation path.

Fig. 9 shows the test apparatus we have developed to do these tests. A motorized polar-mount telescope tracker is used to continuously aim the test article toward the sun. Two singlecell receivers are located in the focal lines of two lenses which were molded directly onto a single piece of ceria-doped microsheet glass. The cells are mounted to an aluminum sheet heat sink, which is movable through a nominal U-shaped articulation path for different beta angles from $-50^{\circ}$ to $+50^{\circ}$. At each $10^{\circ}$ increment in beta angle, the articulation path can be varied from closer to the lens to further from the lens using slots in the 3D-printed white prototype concentrator. Another 3Dprinted gnomon with shadow circles at each $10^{\circ}$ increment is used to measure the beta angle after the prototype concentrator is rotated in the beta angle direction. The short-circuit current of the cell under test is used to measure the lens optical performance. For each data point, three different short-circuit currents are measured for the cell under test:

1. With the lens in place focusing onto the cell.

2. With the cell moved in front of the lens exposed to total (direct and diffuse) solar irradiance.

3. With the cell moved in front of the lens exposed only to diffuse solar irradiance by blocking the direct solar irradiance.

The difference between the second and third current measurements represents the one-sun current due to direct solar irradiance alone. Since the lens can only focus the direct solar irradiance, the ratio of the first current measurement to the difference between the second and third current measurements provides the net concentration ratio for the test. The geometric concentration ratio of the prototype concentrator equals the aperture width of each lens $(5 \mathrm{~cm})$ divided by the active width of each cell $(1.4 \mathrm{~cm})=3.57 \mathrm{X}$, slightly lower than the nominal design value of $4 \mathrm{X}$. The prototype cells are $1.5 \mathrm{~cm}$ in total width but the busbar and the tabs reduce the active width by $7 \%$ to $1.4 \mathrm{~cm}$. The lens net optical efficiency is the ratio of net concentration ratio to geometric concentration ratio.

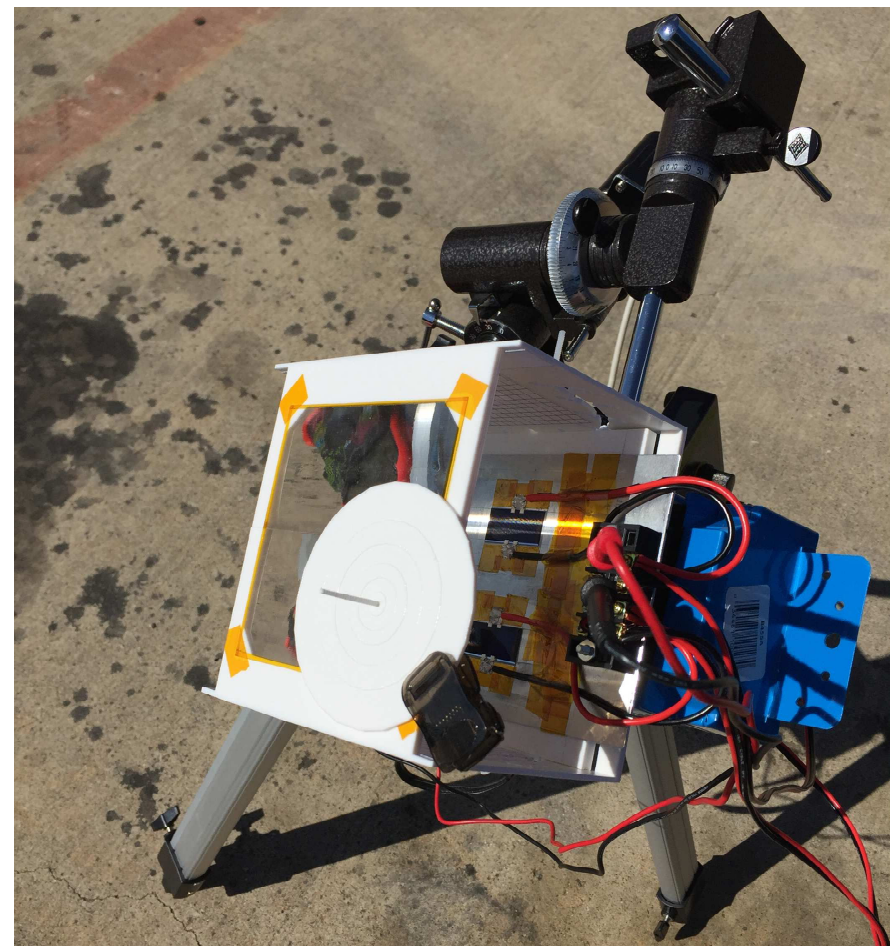

Fig. 9. Beta Articulation Path Outdoor Test Apparatus. 
Fig. 10 shows a close-up of the concentrator during the $25^{\circ}$ beta angle test. Fig. 11 shows the corresponding total solar irradiance one-sun test of the cell at $25^{\circ}$ beta angle. Fig. 12 shows the concentrator test at $50^{\circ}$ beta angle. The nominal Ushaped path for receiver articulation is visible on the right side of the prototype concentrator in Fig. 12, with a nylon threaded rod and wingnuts securing the position. Slots to vary the position from closer to the lens to further away from the lens are also visible.

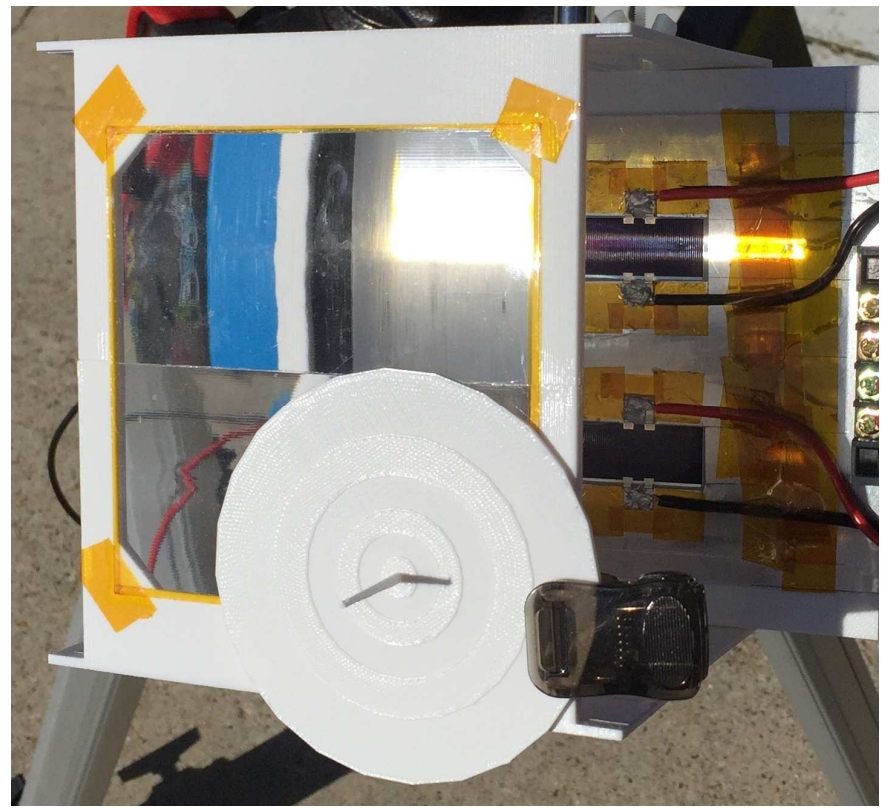

Fig. 10. Concentrator Test at $25^{\circ}$ Beta Angle.

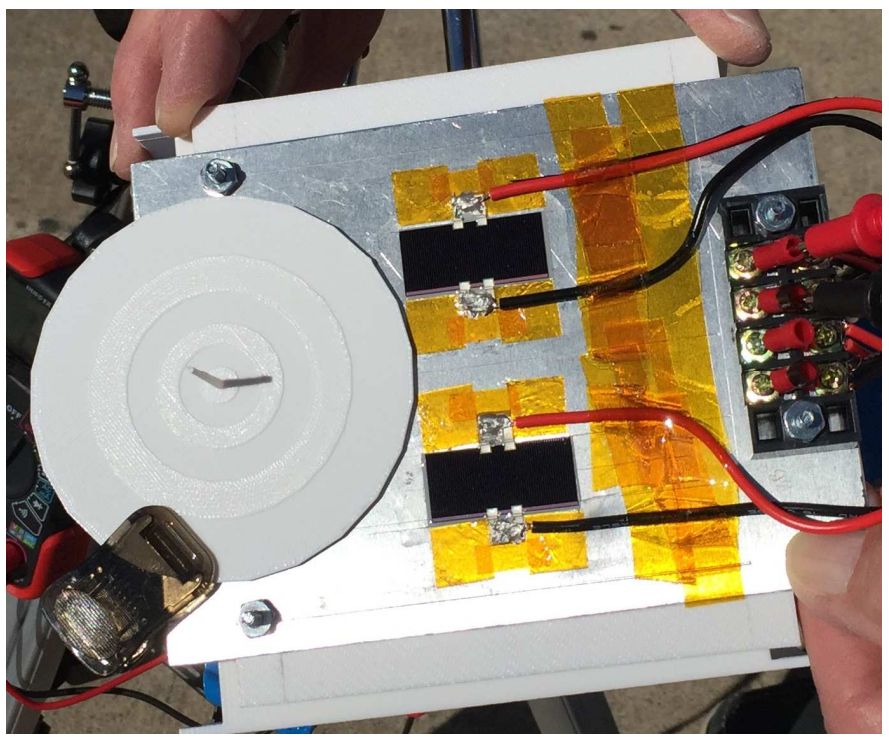

Fig. 11. One-Sun Test at $25^{\circ}$ Beta Angle.

Fig. 13 shows the concentrator test for a zero beta angle. A grid is visible in this photo on the inner wall of the concentrator module. This grid is used to visually align the photovoltaic cell plane to be parallel to the lens plane.

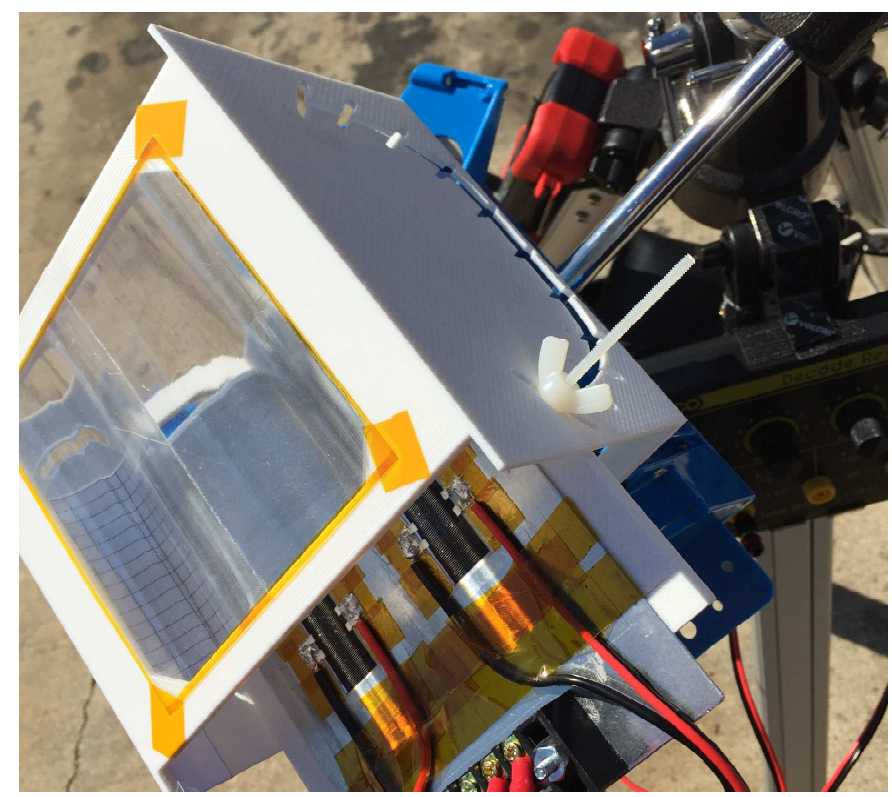

Fig. 12. Concentrator Test at $50^{\circ}$ Beta Angle.

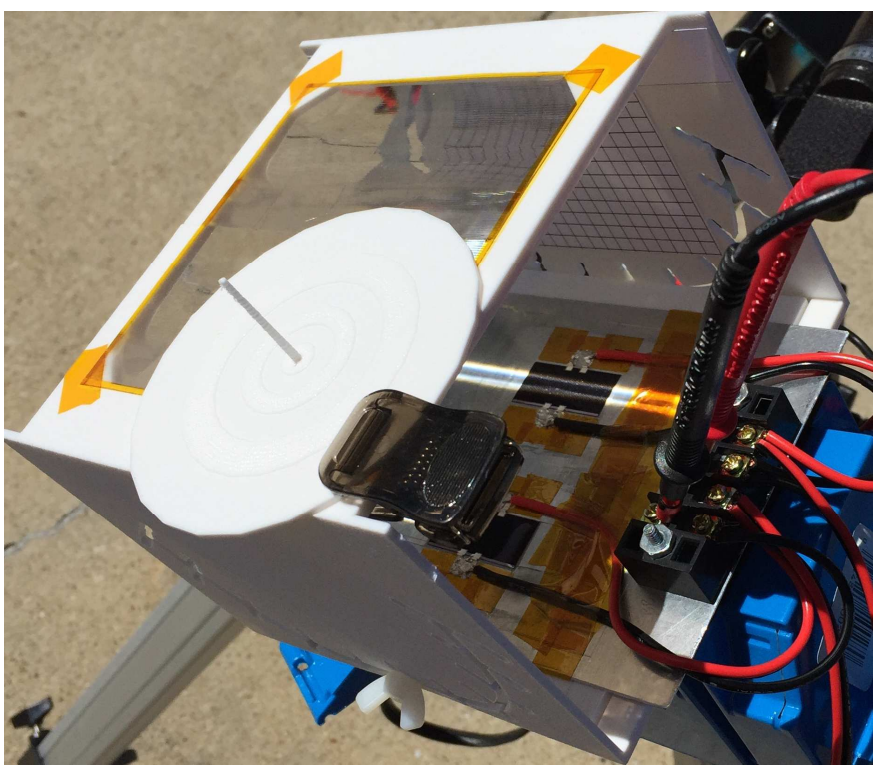

Fig. 13. Concentrator Test at Zero Beta Angle.

Fig. 14 shows the measured net lens optical efficiency versus beta angle for the nominal receiver articulation path, and compares the measured results to predicted results. Two predicted curves are shown, the higher with zero absorption/scattering loss and the lower with $2 \%$ absorption/scattering loss (more realistic). The experimental data are shown with $\pm 4 \%$ error bars, a rough estimate of the probable error in these measurements. Note the greatly expanded non-zero vertical axis in the graph. The predicted and measured results show excellent agreement.

Fig. 15 shows the results of varying the articulation path for $50^{\circ}$ beta angle. Note that the nominal path is best, which measurements at other beta angles also confirmed. 


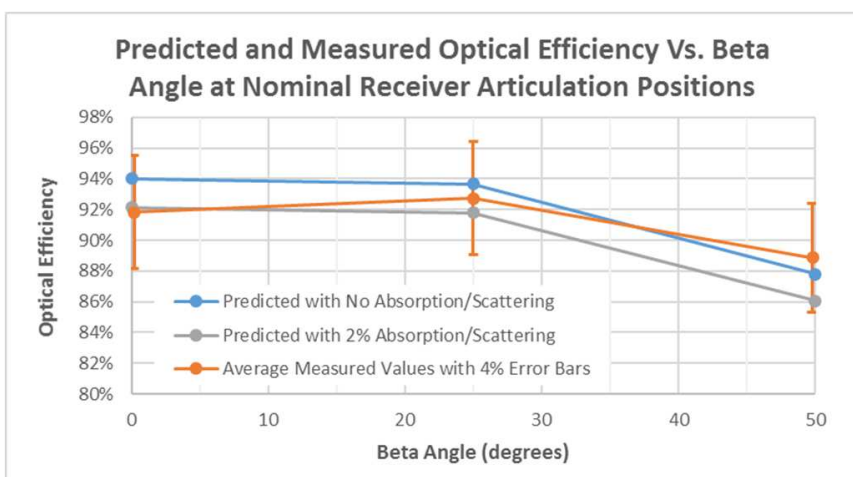

Fig. 14. Measured and Predicted Net Lens Optical Efficiency Versus Beta Angle.

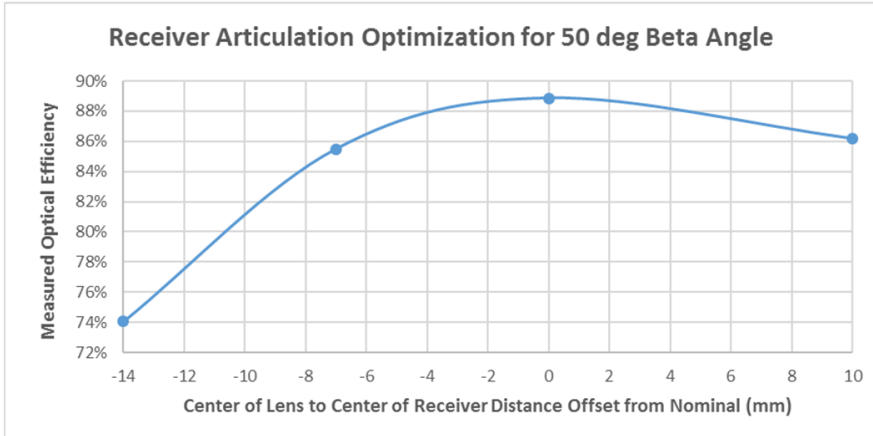

Fig. 15. Receiver Articulation Path Variation from Nominal at $50^{\circ}$ Beta Angle.

\section{UPDATED MASS AND PERFORMANCE METRICS}

A refined areal mass density estimate for the three key concentrator blanket elements is shown in Table 1. These key elements are the lens, heavily shielded photovoltaic receiver (150-micron equivalent coverglass front and back), and graphene radiator. Later in the program we will also estimate the remaining array mass elements for the complete solar array wing, including the solar array deployment and support platform being developed by DSS using their patented roll-out solar array approach [4]. For the limited elements shown in Table 1, the total areal mass density if about $\mathbf{0 . 4 3} \mathbf{~ k g} / \mathbf{m}^{2}$.

\begin{tabular}{|c|c|c|c|c|c|c|}
\hline \multicolumn{7}{|c|}{$\begin{array}{c}\text { Areal Mass Density for } 4 \text { X Line-Focus SLA with Glass/Silicone Lens, Graphene Radiator } \\
\text { Sheet, and Photovoltaic Receiver Elements for IM M Cell with } 150 \text { micron (6 mil) Equivalent } \\
\text { Cover Glass Shielding Front and Back }\end{array}$} \\
\hline \multicolumn{2}{|c|}{ Geometric Concentration Ratio } & \multirow{2}{*}{\begin{tabular}{|l|}
$4.00 X$ \\
$5.00 \mathrm{~cm}$ \\
\end{tabular}} & \multicolumn{3}{|c|}{ Physical Concentration Ratio } & \multirow{2}{*}{\begin{tabular}{|c|}
$3.03 \mathrm{X}$ \\
$1.65 \mathrm{~cm}$ \\
\end{tabular}} \\
\hline & Aperture Width & & Cell Width & $1.45 \mathrm{~cm}$ & $\begin{array}{c}\text { Receiver } \\
\text { Width }\end{array}$ & \\
\hline $\begin{array}{c}\text { Major } \\
\text { Subsystem }\end{array}$ & Element & $\begin{array}{l}\text { Element } \\
\text { Area per } \\
\text { sq.m. } \\
\text { Aperture }\end{array}$ & Thickness & Density & $\begin{array}{c}\text { Mass/ } \\
\text { Aperture }\end{array}$ & $\begin{array}{c}\text { Subtotals: } \\
\text { Mass/Aperture }\end{array}$ \\
\hline & & (sq.m.) & (cm) & (g/cu.cm.) & (kg/sq.m.) & (kg/sq.m.) \\
\hline Lens & 50 micron $\mathrm{CMG} / 50$ micron Silicone & 1.000 & 0.010 & 1.790 & 0.179 & 0.179 \\
\hline Radiator & Silicone-Coated Graphene Radiator & 1.000 & 0.005 & 1.420 & 0.071 & 0.071 \\
\hline \multirow{5}{*}{ Receiver } & CMG Microsheet Cover Glass & 0.330 & 0.008 & 2.550 & 0.063 & \multirow{5}{*}{0.177} \\
\hline & Cover Glass Adhesive & 0.330 & 0.003 & 1.030 & 0.009 & \\
\hline & IMM Cell & 0.330 & 0.001 & 5.300 & 0.017 & \\
\hline & Glass Carrier & 0.330 & 0.008 & 2.550 & 0.063 & \\
\hline & Thermally Conductive Adhesive & 0.330 & 0.005 & 1.500 & 0.025 & \\
\hline
\end{tabular}

Table 1. Areal Mass Breakdown of Lens + Receiver + Radiator.
As discussed above, SolAero has recently developed and produced a pilot run of 4-junction IMM cells for the new concentrator. The average one-sun efficiency (AM0 spectrum, room temperature) of these cells was approximately $31 \%$ on a total area basis, or $33 \%$ on an active area basis. With the normal anticipated gain in performance at the $4 \mathrm{X}$ concentration of the new concentrator, the average cell efficiency should be about $35 \%$. With the $92 \%$ lens efficiency from the tests described above, the combined lens-cell efficiency should be about $32 \%$. While there will of course be additional loss factors for the array, including cell operating temperature effects, wiring and mismatch losses, etc., a target beginningof-life blanket efficiency value of $28 \%$ for higher earth orbits is reasonable, yielding an areal power density of about $380 \mathrm{~W} / \mathrm{m}^{2}$. With the $0.43 \mathrm{~kg} / \mathrm{m}^{2}$ areal mass value for the lens plus heavily shielded photovoltaic receiver plus radiator combination from Table 1, this yields approximately $900 \mathrm{~W} / \mathbf{k g}$ at the blanket level, a remarkable number.

Compared to a conventional one-sun space array, the new concentrator uses about $75 \%$ less of the expensive IMM cell area to produce each Watt of power in space. Since the remaining concentrator blanket materials (glass, silicone, graphene, etc.) are relatively reasonable in cost, a realistic target cost for the new concentrator array is at least $\mathbf{5 0 \%}$ lower than for a one-sun array of the same power rating. Compared to a conventional one-sun space array, the areal mass density of the concentrator blanket is less than half the value for the one-sun array, and the specific power at the blanket level is more than double the value for the one-sun array.

\section{ACKNOWLEDGEMENT}

The work reported in this paper was made possible by a NASA Phase II SBIR contract from NASA GRC to Mark O'Neill, LLC. Our team is grateful to NASA for supporting this work. We are also grateful to Dr. Scott Messenger of SRM Consulting and Dr. Dave Wilt of the Air Force Research Lab (AFRL) for their important contributions in radiation testing and optical property measurements, respectively.

\section{REFERENCES}

[1] Philip Jenkins et al., "Initial Results from the TacSat-4 Solar Cell Experiment," 39th IEEE PVSC, 2013.

[2] Mark O'Neill et al., "Development of More Robust Stretched Lens Array (SLA) Technology with Improved Performance Metrics and Significantly Expanded Applications," 23rd Space Photovoltaic Research and Technology (SPRAT) Conference, 2014.

[3] Mark O'Neill et al., "Recent Space PV Concentrator Advances: More Robust, Lighter, and Easier to Track," 42nd IEEE PVSC, New Orleans, 2015.

[4] Brian Spence et al., "Rollable and Accordion Foldable Refractive Concentrator Space Solar Array Panel, U.S. Patent 8,636,253, 2014. 